\title{
Interactive Effects of Cabbage Aphid and Caterpillar Herbivory on Transcription of Plant Genes Associated with Phytohormonal Signalling in Wild Cabbage
}

\author{
Yehua Li ${ }^{1}$ • Marcel Dicke ${ }^{1}$ - Anneke Kroes ${ }^{1}$ - Wen Liu ${ }^{1} \cdot \operatorname{Rieta}_{\text {Gols }}{ }^{1}$ \\ Received: 4 February 2016 /Revised: 1 June 2016/Accepted: 7 July 2016 / Published online: 16 August 2016 \\ (C) The Author(s) 2016. This article is published with open access at Springerlink.com
}

\begin{abstract}
Plants are commonly attacked by a variety of insect herbivores and have developed specific defenses against different types of attackers. At the molecular level, herbivorespecific signalling pathways are activated by plants in response to attackers with different feeding strategies. Feeding by leaf-chewing herbivores predominantly activates jasmonic acid (JA)-regulated defenses, whereas feeding by phloemsucking herbivores generally activates salicylic acid (SA)-regulated defenses. When challenged sequentially by both phloem-sucking and leaf-chewing herbivores, SA-JA antagonism may constrain the plant's ability to timely and adequately divert defense to the second herbivore that requires activation of a different defensive pathway. We investigated the effect of the temporal sequence of infestation by the aphid Brevicoryne brassicae and three caterpillar species, Plutella xylostella, Pieris brassicae, and Mamestra brassicae, on the interaction between JA and SA signal-transduction pathways in three wild cabbage populations. We found no support for SA-JA antagonism, irrespective of the temporal sequence of herbivore introduction or the identity of the caterpillar species based on the transcript levels of the JA- and SA-regulated marker genes $L O X$ and $P R-1$, respectively, at the examined time points, 6,24 , and $48 \mathrm{~h}$. In general, infestation with aphids alone had little effect on the transcript levels of the two marker genes, whereas the three caterpillar species upregulated not only $L O X$ but also $P R-1$. Transcriptional changes were different for plants from the three different natural cabbage populations.
\end{abstract}

Rieta Gols

rieta.gols@wur.nl

1 Laboratory of Entomology, Wageningen University, P.O. Box 16, 6700 AA, Wageningen, The Netherlands
Keywords Aphid infestation · Caterpillar infestation · Gene transcription - Genotypic variation · Plant defense . SA-JA antagonism

\section{Introduction}

Plants live in a hostile environment and are challenged by a diverse range of attackers, including microbial pathogens and insect herbivores that may attack the plant either simultaneously or sequentially. To cope with the diversity of biotic threats that may reduce the survival and fitness of plants, they are equipped with traits that prevent or reduce attack by biotic agents. These traits, both physical and chemical, can be constitutively expressed or may be activated or enhanced upon attack (Agrawal 1999; Dicke and Baldwin 2010; Karban and Baldwin 1997). To respond adequately to biotic threats, plants need to detect and differentiate between different attacker species. Following the perception and recognition of the attacking herbivore, plants activate an herbivore-specific signal-transduction network that leads to biochemical and physiological changes (De Vos et al. 2005; Erb et al. 2012; Wu and Baldwin 2009, 2010).

Specificity in the response to attackers allows plants to mount a defense that can more effectively cope with herbivore species with distinct life styles and feeding strategies (Howe and Jander 2008; Pieterse et al. 2009). Leaf chewing and phloem feeding insect herbivores are particularly well studied in relation to defense induction in plants. Leaf chewers remove plant tissues and can cause severe damage to plants, whereas piercing-sucking phloem-feeding herbivores feed more subtly, causing only minimal physical damage to plant tissues (Schoonhoven et al. 2005). At the molecular level, defenses against leaf-chewing and phloem-feeding herbivores are regulated by two major signal-transduction pathways 
controlled by the phytohormones jasmonic acid (JA), and salicylic acid (SA). Chewing herbivores generally activate defense responses regulated by JA, whereas piercingsucking herbivores activate defense responses regulated by SA, although this generalization may oversimplify the complex interplay between hormone-regulated induced defenses (Howe and Jander 2008; Kessler and Baldwin 2002; Mewis et al. 2005; Thaler et al. 2012).

When plants are challenged by multiple herbivore species, crosstalk between defense-related phytohormonal signalling pathways may occur, which can help plants to fine-tune their response timely and plastically to the attackers encountered (Howe and Jander 2008; Pieterse et al. 2009; Stam et al. 2014). The best studied interaction between phytohormonal signalling pathways is the antagonistic interaction between JA- and SA-mediated signalling. The activation of the JA signalling pathway may interfere with the SA signalling pathway and vice versa when challenged simultaneously by leafchewing and phloem-feeding herbivores (Koornneef and Pieterse 2008; Pieterse et al. 2012; Thaler et al. 2012). The ecological consequence of this negative SA-JA crosstalk includes e.g., the enhanced performance of caterpillars and their parasitoids on aphid-infested plants as a result of the interference of SA signalling with JA-induced plant defenses ( $\mathrm{Li}$ et al. 2014; Rodriguez-Saona et al. 2010; Soler et al. 2012). The negative interaction between JA- and SA-mediated signalling suggests that plants are constrained in their ability to cope with attack by multiple herbivore species that induce different signalling pathways.

The temporal sequence of herbivory may determine the outcome of the SA-JA crosstalk (Mouttet et al. 2013). For instance, a study on Nicotiana attenuata showed that the order of attack by phloem-feeding mirids and leaf-chewing tobacco hornworms is an important determinant explaining the differences in plant transcriptional responses (Voelckel and Baldwin 2004). Moreover, the leaf chewing Spodoptera frugiperda negatively affected the colonization of maize plants by the root feeder Diabrotica virgifera, but only when the leaf herbivore arrived earlier than the root herbivore (Erb et al. 2011). Thus, when attacked by different species sequentially, the kinetics of the plant's response to the first attacker may limit the ability of the plant to divert its response to a second attacker that activates a different signal-transduction pathway. However, in Lima bean plants, the order of attack by JA-activating spider mites and SA-activating whiteflies (Bemisia tabaci) did not exhibit major effects on induced plant responses (Zhang et al. 2009). Similarly, the performance of B. tabaci was not affected by pre-infestation by a chewing leaf miner (Tuta absoluta) in tomato (Mouttet et al. 2013). However, in the same study system, pre-infestation with either whiteflies or a fungal biotrophic pathogen (Oidium neolycopersici), which also is associated with SA-regulated defense induction, negatively impacted the development of the leaf miner. These effects were either only locally expressed in the induced leaf (response to whiteflies) or both locally and systemic (response to pathogen) (Mouttet et al. 2013). These examples also suggest that the outcome of plant-mediated species interactions can be highly context-specific.

Although herbivores of the same feeding guild generally trigger the same major signalling pathway (Erb et al. 2012), plant responses to species of the same feeding guild are not exactly the same (Bidart-Bouzat and Kliebenstein 2011), which likely is the result of modulation of defense responses due to crosstalk at the molecular level (De Vos et al. 2005). For example, feeding by various lepidopteran species resulted in differential induction of the three major phytohormones involved in induced plant responses, as well as differential transcriptional responses (Diezel et al. 2009; Poelman et al. 2011; Zhu et al. 2015).

Closely related plant species may vary in their responses to the same type of herbivory (Schmidt et al. 2005). Moreover, within one species, heritable variation in resistance traits is an important component in the adaptation of plants to environmental stresses (Gols et al. 2008; Newton et al. 2009a; Wu and Baldwin 2010). Intraspecific variation was found for plant secondary metabolites, such as glucosinolates in brassicaceous plant species, in Arabidopsis thaliana accessions and wild cabbage, Brassica oleracea, populations ( Gols et al. 2008; Kliebenstein et al. 2001; Newton et al. 2009b) and crosstalk between SA- and JA-regulated defenses differed among A. thaliana accessions (Pieterse and Dicke 2007; Pieterse et al. 2009; Traw et al. 2003). In two accessions of $N$. attenuata, large differences in herbivory-induced early signalling events, such as MAPK activity, JA and ethylene production, and transcript accumulation of genes that encode transcription factors were recorded (Wu et al. 2008). Therefore, the underlying regulatory mechanisms of plant defense may vary among plant genotypes and populations.

The aim of this study was to investigate whether aphid- and caterpillar-induced plant responses interfere with each other through negative SA-JA crosstalk in different populations of wild cabbage. Underlying mechanisms that explain plant responses to herbivory rely to a large extent on studies performed on A. thaliana (De Vos et al. 2005; Koornneef and Pieterse 2008; Kroes et al. 2015; Pieterse et al. 2009). The question is to what extent the results of these studies are representative for plant responses to herbivory in general or for brassicaceous plants more specifically, as the interaction of Arabidopsis with herbivores in nature is limited due to their short life cycle early in the growing season (Harvey et al. 2007).

In this study, we used plants grown from seeds that originated from three wild cabbage populations that are known to differ in secondary plant chemistry (Gols et al. 2008; Harvey et al. 2011; Newton et al. 2009a), and interact in nature with the herbivores used in this study, the aphid Brevicoryne 
brassicae L. (Hemiptera, Aphididae), and three chewing lepidopteran species, caterpillars of Plutella xylostella (L.) (Plutellidae), Pieris brassicae L. (Pieridae), and Mamestra brassicae L. (Noctuidae), respectively (Newton et al. 2009b). We addressed the following questions: 1) What is the effect of the sequence of herbivore attack on SA-JA crosstalk? 2) How general is this response when using different species of chewing herbivores? and 3) Is there intraspecific variation in the plant's responses to herbivory by aphids and caterpillars? We quantified the transcript levels of two marker genes related to JA- and SA-signalling, i.e., LIPOXYGENASE (LOX) and PATHOGENESIS-RELATED PROTEIN-1 (PR-1), respectively (Bell et al. 1995; Jirage et al. 2001), at different time points following inoculation by each of the three different chewing herbivore species and the piercing-sucking aphid when introduced alone, simultaneously, or sequentially on wild cabbage plants from populations.

\section{Materials and Methods}

Plants and Insects Seeds of wild cabbage (Brassica oleracea) populations were collected in Dorset, U.K., at sites known as Kimmeridge $\left(50^{\circ} 36^{\prime} \mathrm{N}, 2^{\circ} 07^{\prime} \mathrm{W}\right)$, Old Harry $\left(50^{\circ} 38^{\prime} \mathrm{N}, 1^{\circ} 55^{\prime} \mathrm{W}\right)$, and Winspit $\left(50^{\circ} 35^{\prime} \mathrm{N}, 2^{\circ} 02^{\prime}\right.$ $\mathrm{W})$, hereafter called $\mathrm{KIM}, \mathrm{OH}$, and WIN, respectively. At each site, 20 plants were randomly selected for seed collection, and the seeds were pooled per site. Plants were grown from seeds in 1.5 -L pots (1 plant per pot) containing potting soil (Lentse potgrond no. 4; Lent, The Netherlands) in a greenhouse $\left(22 \pm 3{ }^{\circ} \mathrm{C}, 50-\right.$ $70 \%$ relative humidity [RH], light:dark regime [L:D] $16: 8 \mathrm{~h})$. Plants were placed in large trays $(675 \times 170 \mathrm{~cm})$ that were automatically flooded with water and nutrients (NH4 1.2, K 7.2, Ca 4.0, Mg 1.82, NO3 12.4, SO4 3.32, P 1.0, Fe 35.0, Mn 8.0, $\mathrm{Zn} \mathrm{5.0,} \mathrm{B} \mathrm{20.0,} \mathrm{Cu} \mathrm{0.5,} \mathrm{Mo} 0.5$ in $\mathrm{mmol} / \mathrm{L}$ ) once every day for $20 \mathrm{~min}$.

Except for $M$. brassicae, all other herbivore species (B. brassicae, P. xylostella, and P. brassicae) are specialist feeders on brassicaceous plant species, although $M$. brassicae is considered a pest on cabbage crops like the other three herbivore species. All insect cultures were maintained on Brussels sprouts ( $B$. oleracea L. var. gemmifera cv. Cyrus) plants in a greenhouse or a climate room at $22 \pm 2{ }^{\circ} \mathrm{C}, 60-70 \% \mathrm{RH}$ and 16:8 h L:D photoregime.

General Treatment and Sampling Protocol In a pilot experiment, we first determined the amount of damage inflicted in $24 \mathrm{~h}$ by each caterpillar species, and then adjusted the number of caterpillars per species to standardize the consumed area of leaf tissues. We used a transparent plastic sheet with a $1-\mathrm{mm}^{2}$ grid to quantify the area of the consumed leaf tissue in $\mathrm{mm}^{2}$. Results of the pilot showed that three 2-d-old second instar (L2) $P$. xylostella, four 1-d-old L1 M. brassicae, and three neonate $P$. brassicae larvae, respectively, consume similar amounts of leaf tissue $(P$. xylostella, $53 \pm 4.6$; M. brassicae, $59 \pm 6.0 ;$ P. brassicae, $49.9 \pm 2.3 \mathrm{~mm}^{2}$ ) in $24 \mathrm{~h}$. These numbers of caterpillars were used to inoculate the plants in the experiments described below. The initial inoculation density of $B$. brassicae was set at 8 adult aphids per plant.

Plants were exposed to herbivory treatments when they were $4 \mathrm{wk}$. old, and had 3-6 expanded leaves. Insects were introduced onto the first fully expanded leaf. To confine the insects to this leaf, the leaf petiole was wrapped with cotton wool. In each of the three experiments described below, one set of plants served as a control and was not exposed to herbivory, but was otherwise treated similarly. Plants of the three cabbage populations, exposed to different herbivory treatments, were placed randomly on the tables in a greenhouse. For gene-transcript quantification, per plant two leaf discs were punched with a cork-borer (diam $1.8 \mathrm{~cm}$ ) from the herbivore-exposed leaves, and leaf discs were collected from three plants and pooled (=one replicate sample). Insects remained on the plants during the various exposure periods, and were only removed just before leaf sample collection. Twelve plants were prepared to obtain four replicate samples in total for each plant population, herbivore treatment, and timepoint combination (see below). At each time point, an equal number of samples was collected from control plants, and a new cohort of control plants was used at each time point. Plants were sampled only once, i.e., distinct groups of plants were prepared for each timetreatment combination. Immediately after sample collection, samples were flash-frozen in liquid nitrogen and stored in a freezer at $-80{ }^{\circ} \mathrm{C}$ until further processing for qRT-PCR.

\section{Experiment 1: Single Vs. Dual Infestation with} B. brassicae Aphids and $\boldsymbol{P}$. xylostella Caterpillars Plants were inoculated with either B. brassicae (B) or P. xylostella $(\mathrm{Px})$, or a combination of simultaneous $B$. brassicae and P. xylostella inoculation $(\mathrm{Px}+\mathrm{B})$. Samples for gene expression were collected at 6,24 , and $48 \mathrm{~h}$ after introduction of the herbivores as described in the previous section.

Experiment 2: Effect of the Order of Arrival of $B$. brassicae Aphids and P. xylostella Caterpillars Plants initially were inoculated with B. brassicae aphids or P. xylostella caterpillars, or left free of herbivores. The insects were allowed to feed and reproduce (aphids only) for $5 \mathrm{~d}$. 
Following this incubation with the first herbivore, half of the plants that were exposed to each of the two herbivore treatments were co-infested with the other herbivore (coded BPx and $\mathrm{PxB}$ ), whereas the remaining half of the plants were left as they were (B and Px). In addition, cohorts of plants that had not been exposed to herbivores previously, were inoculated with either B. brassicae or P. xylostella caterpillars (CB and $\mathrm{CPx})$. Samples for gene expression were collected from all plants including controls (=without any herbivory) at 24 and $48 \mathrm{~h}$ after the second herbivore had been introduced.

\section{Experiment 3: Effect of Sequential Infestation with} B. brassicae Aphids and Caterpillars of Different Herbivore Species Sets of plants were or were not inoculated with $B$. brassicae aphids, and were incubated for $5 \mathrm{~d}$, and then were infested with caterpillars of one of three different lepidopteran species, i.e., P. xylostella, P. brassicae, or M. brassicae (without aphids $\mathrm{CPx}, \mathrm{CPb}$, and $\mathrm{CMb}$, and with aphids $\mathrm{BPx}, \mathrm{BPb}$, and $\mathrm{BMb}$ ). Samples for gene expression were collected from all plants including controls (=without any herbivory) at 24 and $48 \mathrm{~h}$ after the second herbivore had been introduced.

\section{RNA Isolation and Real-Time Quantitative Reverse} Transcription PCR (qRT-PCR) Samples were kept frozen with liquid nitrogen, and ground to a fine powder with a mortar and pestle. RNA was isolated from homogenized material by using RNeasy Plant Mini Kit (Qiagen), and were treated with DNAsel (Invitrogen) following the manufacturer's instructions. After isolation, the RNA concentration and purity were measured using a NanoDrop ND-100 (NanoDrop Technologies, Wilmington, DE, USA) spectrophotometer (all samples with OD $260 \mathrm{~nm} / 280 \mathrm{~nm}$ of 1.9-2.2 ratio). RNA integrity numbers (RIN) of randomly selected samples were confirmed by Bioanalyzer (Agilent 2100) with the Agilent RNA 6000 Nano Kit (Agilent Technologies, Waldbronn, Germany). The concentration of RNA obtained from the plant material was adjusted to $1 \mu \mathrm{g} / \mu \mathrm{l}$, and subsequently was reverse-transcribed into cDNA with the iScript cDNA synthesis Kit (BioRad). RNA samples were randomly selected for a negative control cDNA reaction by omitting the reverse transcriptase, to ensure that no samples were contaminated with genomic DNA. Quantitative ReverseTranscriptase PCR (qRT-PCR) analysis was performed

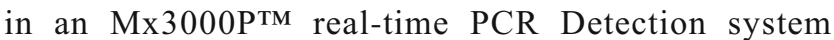
(Rotorgene). The qPCR amplification mix consisted of: $12.5 \mu \mathrm{l}$ of SYBER Green Supermix (Bio-Rad), $5 \mu \mathrm{l}$ cDNA, $5.5 \mu \mathrm{l}$ DEPC-treated water, and $10 \mathrm{pmol}$ of each primer in $1 \mu \mathrm{l}$ each (see Table 1, Wageningen, The Netherlands) adding up to a total volume of $25 \mu \mathrm{l}$. The primers of the two tested genes were designed based on those used in the study by Zheng et al. (2007) and Poelman et al. (2011). The amplification efficiency of primers was determined by generating standard curves using a 10-fold dilution of the randomly selected samples per treatment and per cabbage population. Each dilution was assayed in triplicate. The amplification efficiency was between 90 and $100 \%$ for all primer pairs tested on the three cabbage populations. For each cDNA sample, qPCR amplification reactions were performed in duplicate. The following PCR program was used for all amplification reactions: an initial denaturation step of $3 \mathrm{~min}$ at $95{ }^{\circ} \mathrm{C}$, followed by $40 \mathrm{cy}$ cles of $15 \mathrm{~s}$ at $95{ }^{\circ} \mathrm{C}, 45 \mathrm{~s}$ at $59{ }^{\circ} \mathrm{C}$. At the end of each run, melting curve analysis was performed to verify that only a single gene transcript had been amplified. Relative gene transcript levels were calculated by normalizing transcript levels to the threshold cycle $(\mathrm{Ct})$ values of the reference gene GAPDH using the $2^{-\Delta \Delta C t}$ method (Livak and Schmittgen 2001). The Ct values of the reference gene GAPDH were consistent across treatments.

Statistics The response variables, relative transcript levels of $L O X$ and $P R-1$, were log-transformed to meet assumptions of normality and homoscedasticity. Data were analyzed using General Linear Model analysis of variance in Genstat (17th edition, VSN International, Hemel Hempstead, UK). In experiments 1 and 2, plant population, herbivore treatment and time points were entered as fixed factors in the statistical model. The data of experiment 2 were split into two sets: data of gene transcript levels of control plants and those exposed to aphid infestation alone (C, $\mathrm{CB}$, and $\mathrm{B})$ were analyzed separately, to confirm the effect of aphid infestation in experiment 1; data of gene transcript levels of plants with caterpillar ( $P$. xylostella) infestation alone and in combination with aphid feeding $(\mathrm{CPx}$, $\mathrm{Px}, \mathrm{BPx}$, and $\mathrm{PxB}$ ) were analyzed to investigate the effect of temporal order of infestation. In experiment 3 , we investigated whether transcript levels of the two genes were similarly affected by the infestation of different caterpillar species, both in the presence and absence of aphid feeding. In addition to population and time points, caterpillar species and presence / absence of aphids were entered as fixed terms in the statistical model. When terms in the GLM were significant, pairwise differences among factor levels were determined using Tukey-Kramer-corrected LSD tests.

\section{Results}

Experiment 1: Single Vs. Dual Infestation with B. brassicae Aphids and P. xylostella Caterpillars - LOX Expression There was a significant effect of herbivore treatment, time point, and population on the transcript 
Table 1 Primer sequences used for amplifying Gapdh, Pr-1, And Lox genes of Brassica oleracea

\begin{tabular}{lll}
\hline Gene name & Forward primer & Reverse primer \\
\hline BoGAPDH & 5'-AGAGCCGCTTCCTTCAACATCATT-3' & 5'-TGGGCACACGGAAGGACATACC-3' \\
BoLOX & 5'-AAGGCATCGAGCTTCCCAA-3' & 5'-TTGCTTTTCAACGGCCACTC-3' $^{\prime}$ BoPR-1 \\
\hline
\end{tabular}

levels of $L O X$ (Table 2, Fig. 1a-c). Feeding by P. xylostella caterpillars alone or in combination with $B$. brassicae aphids (Fig. 1a) similarly up-regulated the expression of $L O X$ (Px vs. $\mathrm{Px}+\mathrm{B}, P=0.32$ ), whereas transcript levels of $L O X$ were similar in the controls and in plants exposed to B. brassicae alone (C vs. B, $P=0.71)$. The marginally significant interaction between herbivore treatment and plant population further indicated that the extent to which $L O X$ was transcribed was somewhat plant-population specific. The relative expression of $L O X$ in caterpillar-exposed plants increased with time, and the temporal dynamics of this gene also differed among the populations (Table 2). For example, in KIM plants, $L O X$ transcripts were significantly different only in samples taken at 6 and $48 \mathrm{~h}$ following herbivore introduction (KIM-6 vs. KIM-48, $P=0.02)$, whereas in WIN plants transcript levels differed at both 24 and $48 \mathrm{~h}$ from those at $6 \mathrm{~h}(P<0.001$

Table 2 GLM analysis results of the main effects of wild cabbage (Brassica oleracea) plant population, herbivore treatment, time point and their interaction terms on the transcript level of lox and pr-1 in experiment $1^{\mathrm{a}}$

Experiment 1

\begin{tabular}{lllllc}
\hline Tested gene & Factor & N.d.f. & D.d.f. & $F$ statistic & $P$ value \\
LOX & Plant population (1) & 2 & 107 & 12.57 & $<\mathbf{0 . 0 0 1}$ \\
& Treatment $(2)$ & 3 & 107 & 15.16 & $<\mathbf{0 . 0 0 1}$ \\
& Time point (3) & 2 & 107 & 36.08 & $<\mathbf{0 . 0 0 1}$ \\
& Interaction $1 * 2$ & 6 & 107 & 1.99 & 0.074 \\
& Interaction $1 * 3$ & 4 & 107 & 6.78 & $<\mathbf{0 . 0 0 1}$ \\
& Interaction $2 * 3$ & 6 & 107 & 8.41 & $<\mathbf{0 . 0 0 1}$ \\
PR-1 & Interaction $1 * 2 * 3$ & 12 & 107 & 1.10 & 0.368 \\
& Factor & N.d.f. & D.d.f. & $F$ statistic & $P$ value \\
& Plant population $(1)$ & 2 & 105 & 7.67 & $<\mathbf{0 . 0 0 1}$ \\
& Treatment $(2)$ & 3 & 105 & 7.07 & $<\mathbf{0 . 0 0 1}$ \\
& Time point $(3)$ & 2 & 105 & 3.07 & 0.051 \\
& Interaction $1 * 2$ & 6 & 105 & 1.40 & 0.223 \\
& Interaction $1 * 3$ & 4 & 105 & 4.99 & $\mathbf{0 . 0 0 1}$ \\
& Interaction $2 * 3$ & 6 & 105 & 1.40 & 0.222 \\
& Interaction $1 * 2 * 3$ & 12 & 105 & 1.15 & 0.331 \\
\hline
\end{tabular}

$P$-values in bold denote significant effects

${ }^{a}$ In the statistical model, plant population had three levels (KIM, WIN, $\mathrm{OH}$ ), treatment had four levels (see Fig. 1) and time point had three levels $(6,24$, and $48 \mathrm{~h})$ both comparisons). In $\mathrm{OH}$ plants, the patterns were similar to those in KIM plants, but they were not statistically significant due to the high levels of variation $(6 \mathrm{~h}$ vs. 48 h $P=0.10$ ).

PR-1 Expression The transcript levels of $P R-1$, a SAresponsive marker gene, were affected by herbivore treatment and plant population, and the effect of time point was population specific (Table 2, Fig. 1d-f). The expression of this gene was up-regulated only in KIM plants (KIM vs. OH, $P=0.005$, KIM vs. WIN, $P=0.01$; WIN vs. $\mathrm{OH}, P=0.97$ ), and the transcript levels increased only in response to feeding by P. xylostella alone or in combination with aphids (B vs. C, $P=0.77$, Px vs. Px $+\mathrm{B}, P=0.92$, all other pair-wise comparisons $P<0.05)$. In KIM plants, $P R-1$ transcript levels were higher in tissue sampled at $24 \mathrm{~h}$ than in those sampled at $6 \mathrm{~h}$ following infestation (KIM-6 vs. KIM$24, P=0.007$; all other within population-time point comparisons $P>0.05$ ).

Experiment 2: Effect of the Order of Arrival of $B$. brassicae Aphids and $P$. xylostella Caterpillars In a first analysis including data from control plants (C) and plants infested with aphids ( $\mathrm{CB}$ and $\mathrm{B}$ ) alone (for treatment coding see Fig. 2), we confirmed the results of experiment 1 . The transcript levels of both $L O X$ and $P R-1$ were similar in plants infested by $B$. brassicae alone for a short period, i.e., 1 or 2 days (CB), or an extended period, i.e., 6 or 7 days (B) compared to control plants $(\mathrm{C})$, irrespective of the plant population (Table 3a; Fig. 2). In a second analysis, we investigated the effect of the temporal infestation order of $P$. xylostella caterpillars and $B$. brassicae aphids on gene transcript levels.

LOX Expression Herbivore treatment and plant population had a significant effect on the expression of $L O X$ (Table $3 \mathrm{~b}$, Fig. 2a-c). Overall, the presence of $B$. brassicae had relatively little effect on the expression of $L O X$, regardless of the order of arrival (CPx vs. BPx, $P=0.72$, Px vs. PxB, $P=0.99$, Fig. 2a-c). $L O X$ transcription differed only between plants that were infested with caterpillars first and aphids second and between plants that were infested with caterpillars late, irrespective of whether there were also aphids on the plant $(\mathrm{PxB}$ vs. $\mathrm{CPx}, P=0.02$; PxB vs. $\mathrm{BPx}, P=0.01)$. However, there 

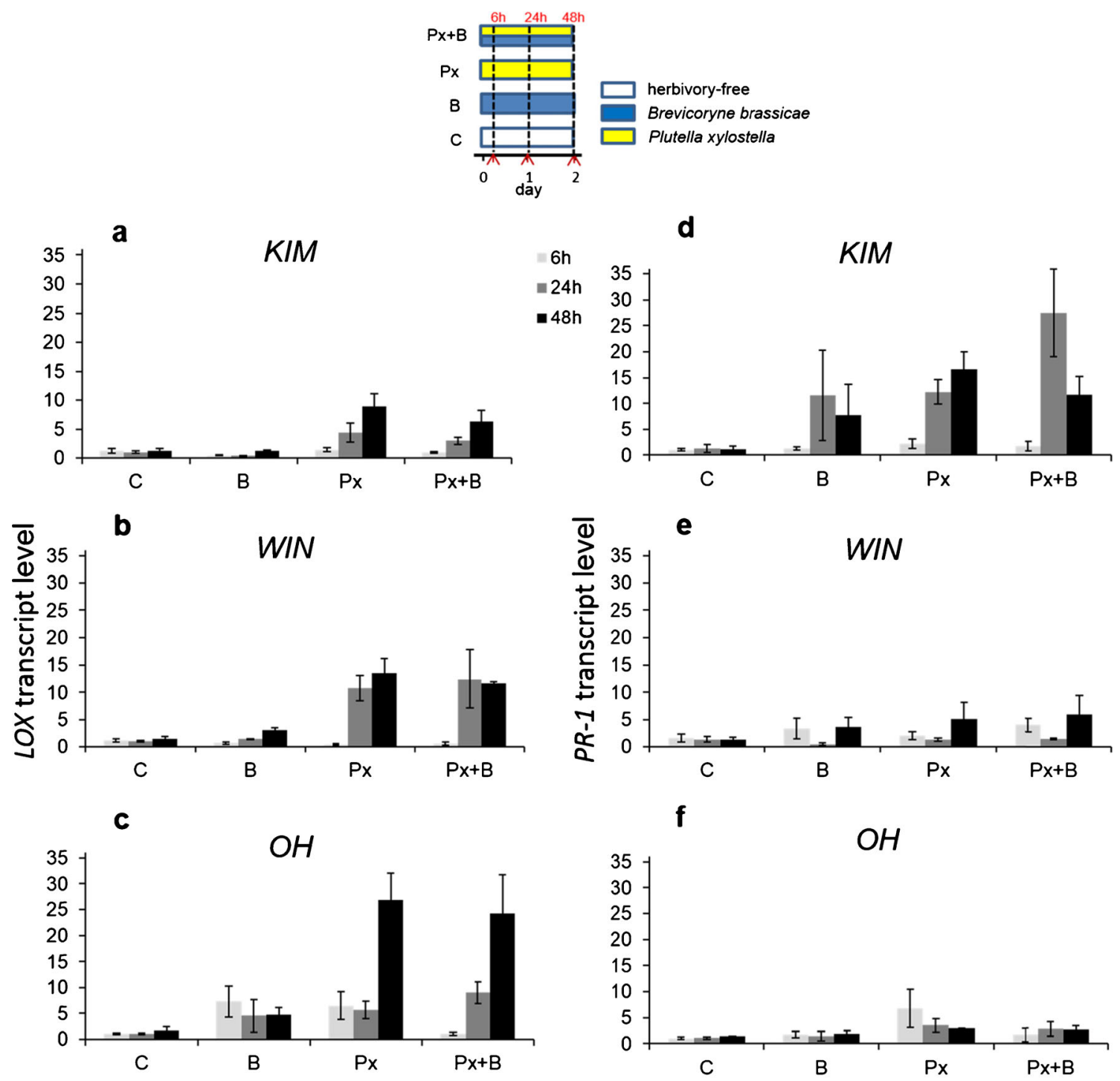

Plant treatment

Fig. 1 Quantitative RT-PCR analysis of transcript levels of the jasmonic acid (JA)-responsive defense marker gene LOX (panels a-c) and the salicylic acid (SA)-responsive defence marker gene $P R-1$ (panels d-f) in leaves of plants from three different wild Brassica oleracea populations (KIM [a;d]; WIN [b;e]; OH [c;f]) at 6, 24, and $48 \mathrm{~h}$ after infestation with Plutella xylostella caterpillars (Px); Brevicoryne brassicae aphids (B); both P. xylostella and B. brassica simultaneously
$(\mathrm{Px}+\mathrm{B})$, or without any herbivory (C). Transcript levels of genes are shown as fold changes in mean relative expression compared to those of control plants $(\mathbf{C})$. Bars present means \pm SE $(N=4)$. The temporal sequence of plant inoculation with different insect herbivore species is given in a schematic overview above the bar graphs. Sampling time points for gene transcript analysis are indicated by the red coloured arrows on the $\mathrm{X}$-axis also was a significant interaction between the time point of sampling and treatment. At both time points, $L O X$ transcript levels were equally high in plants that were infested with caterpillars late, irrespective of the presence of aphids (CPx$24 \mathrm{~h}$ vs. CPx-4 h and BPx-24 h vs. BPx-48 h, $P>0.95$ ). In plants infested with caterpillars early and no aphids, $L O X$ transcript levels were significantly lower at 48 than at $24 \mathrm{~h}$ (Px-24 h vs. Px-48 h, $P=0.006$ ), whereas in plants infested with caterpillars early and aphids late $(\mathrm{PxB})$, transcription levels were equally low at both time points $(P>0.05)$. The late infestation of $B$. brassicae and the extended period of caterpillar feeding tended to suppress the transcript level of $L O X$ (PxB-48 h vs. Px-48 h). $L O X$ transcripts were higher in WIN than in KIM plants, whereas levels of this gene in $\mathrm{OH}$ plants did not differ from those in plants from the other two populations (Fig. 2a-c, WIN vs. KIM, $P=0.01$, OH vs. KIM, $P=0.17$, and $\mathrm{OH}$ vs WIN, $P=0.53$ ). The effect of time point on $L O X$ expression differed among plant populations. The upregulation of $L O X$ was fastest in WIN (levels were higher at $24 \mathrm{~h}$ than at $48 \mathrm{~h}, P=0.006$ ), whereas for the other two 
Table 3 GLM analysis results of the main effects of plant population, herbivore treatments, time point and their interaction terms on the transcript level of lox and $p r-1$ in experiment $2^{\text {a }}$

Experiment 2(a) Treatment of C, CB, B

\begin{tabular}{|c|c|c|c|c|c|}
\hline Tested gene & Factor & N.d.f. & D.d.f & $F$ statistic & $P$ value \\
\hline \multirow[t]{7}{*}{$L O X$} & Plant population (1) & 2 & 53 & 0.30 & 0.739 \\
\hline & Treatment (2) & 2 & 53 & 0.56 & 0.572 \\
\hline & Time point (3) & 1 & 53 & 1.92 & 0.171 \\
\hline & Interaction $1 * 2$ & 4 & 53 & 0.14 & 0.968 \\
\hline & Interaction $1 * 3$ & 2 & 53 & 0.04 & 0.956 \\
\hline & Interaction $2 * 3$ & 2 & 53 & 0.53 & 0.593 \\
\hline & Interaction $1 * 2 * 3$ & 4 & 53 & 0.29 & 0.883 \\
\hline \multirow[t]{8}{*}{$P R-1$} & Factor & N.d.f. & D.d.f & $F$ statistic & $P$ value \\
\hline & Plant population (1) & 2 & 53 & 0.09 & 0.918 \\
\hline & Treatment (2) & 2 & 53 & 0.75 & 0.479 \\
\hline & Time point (3) & 1 & 53 & 0.71 & 0.403 \\
\hline & Interaction $1 * 2$ & 4 & 53 & 0.04 & 0.996 \\
\hline & Interaction $1 * 3$ & 2 & 53 & 1.54 & 0.224 \\
\hline & Interaction $2 * 3$ & 2 & 53 & 0.76 & 0.473 \\
\hline & Interaction $1 * 2 * 3$ & 4 & 53 & 0.60 & 0.664 \\
\hline \multicolumn{6}{|c|}{ Experiment 2(b) Treatment of CPx, Px, BPx,PxB } \\
\hline Tested gene & Factor & N.d.f. & D.d.f & $F$ statistic & $P$ value \\
\hline \multirow[t]{7}{*}{$L O X$} & Plant population (1) & 2 & 72 & 4.33 & 0.017 \\
\hline & Treatment (2) & 3 & 72 & 4.57 & 0.005 \\
\hline & Time point (3) & 1 & 72 & 3.31 & 0.073 \\
\hline & Interaction $1 * 2$ & 6 & 72 & 0.45 & 0.846 \\
\hline & Interaction $1 * 3$ & 2 & 72 & 6.02 & 0.004 \\
\hline & Interaction $2 * 3$ & 3 & 72 & 4.35 & 0.007 \\
\hline & Interaction $1 * 2 * 3$ & 6 & 72 & 0.45 & 0.845 \\
\hline \multirow[t]{8}{*}{$P R-1$} & Factor & N.d.f. & D.d.f & $F$ statistic & $P$ value \\
\hline & Plant population (1) & 2 & 78 & 0.07 & 0.929 \\
\hline & Treatment (2) & 3 & 78 & 0.74 & 0.532 \\
\hline & Time point (3) & 1 & 78 & 5.17 & 0.026 \\
\hline & Interaction $1 * 2$ & 6 & 78 & 0.57 & 0.751 \\
\hline & Interaction $1 * 3$ & 2 & 78 & 1.71 & 0.187 \\
\hline & Interaction $2 * 3$ & 3 & 78 & 3.99 & 0.011 \\
\hline & Interaction $1 * 2 * 3$ & 6 & 78 & 0.52 & 0.793 \\
\hline
\end{tabular}

$P$-values in bold denote significant effects

${ }^{a}$ In the statistical model, plant population had three levels (KIM, WIN, $\mathrm{OH})$, treatment had three levels for experiment 2(a), four levels for experiment 2(b) (see Fig. 2) and time point had two levels (24 and 48 h)

populations, there was no difference between transcript levels at 24 and $48 \mathrm{~h}$ (KIM-24 vs. KIM-48, $P=0.84$, OH-24 vs. OH$48, P=0.99)$.

PR-1 Expression The effect of herbivore treatment on PR-1 transcription depended on the time of sampling (Table $3 \mathrm{~b}$, Fig. 2d-f). $P R-1$ transcript levels did not differ among the plant populations (Table $3 \mathrm{~b}$ ). In the treatments where caterpillars were introduced late, i.e., $\mathrm{CPx}$ and $\mathrm{BPx}, P R-1$ transcript levels were higher at 48 than at $24 \mathrm{~h}$, but this was significant only in the treatment where aphids were introduced first and caterpillars second (BPx-24 vs. BPx-48, $P=0.05)$.

\section{Experiment 3: Effect of Dual Infestation with $B$. brassicae Aphids and Caterpillars of Different Herbivore Species}

LOX Expression The extent to which $L O X$ was up-regulated was affected by caterpillar species, plant population, and the time of sampling, while it was not affected by the presence or absence of feeding aphids (Table 4; Fig. 3a-c). LOX transcript levels were highest in plants infested with $M$. brassicae, intermediate in plants infested with $P$. xylostella, and lowest in plants infested with $P$. brassicae (Fig. 3a-c; $\mathrm{Mb}$ vs. $\mathrm{Pb}$, $P<0.001, \mathrm{Mb}$ vs. Px, $P=0.03$, Px vs. $\mathrm{Pb}, P<0.001)$. Overall, transcript levels of $L O X$ were higher in $\mathrm{KIM}$ and $\mathrm{OH}$ plants than in WIN plants (KIM vs. OH, $P=0.18$, WIN vs. $\mathrm{KIM}$, and WIN vs. $\mathrm{OH}, P<0.001)$, and they were higher at $48 \mathrm{~h}$ than at $24 \mathrm{~h}$ after initiation of caterpillar feeding. However, the extent to which transcript levels increased with time depended on the population; whereas transcript levels were similar at $24 \mathrm{~h}$ following the introduction of the herbivores (all comparisons $P>0.05)$, transcript levels at $48 \mathrm{~h}$ were highest in KIM, intermediate in $\mathrm{OH}$, and lowest in WIN (KIM vs. OH, $P=0.005$, KIM vs. WIN and $\mathrm{OH}$ vs. WIN, $P<0.001)$.

PR-1 Expression The results for transcript levels of $P R-1$ in response to feeding by different caterpillar species in the presence or absence of aphids were more idiosyncratic; two of the four three-way interactions were significant (Table 4, Fig. 3df). Overall, $P R-1$ transcripts increased more in response to M. brassicae than to $P$. xylostella feeding $(P=0.002)$, whereas transcription of this gene was similar in response to $P$. brassicae feeding and feeding by the other two caterpillar species ( $\mathrm{Pb}$ vs. $\mathrm{Px}$ and $\mathrm{Pb}$ vs. $\mathrm{Mb}, P>0.05$ ). Early aphid infestation did not affect transcript levels of $P R-1$ in response to $P$. xylostella and M. brassicae feeding, whereas it had a tendency to decrease $P R-1$ transcript levels in plants infested with $P$. brassicae larvae for $48 \mathrm{~h}$; however, this was not statistically significant. Overall transcript levels of $P R-1$ in $\mathrm{OH}$ plants were higher than in the other two populations $(\mathrm{OH}$ vs. KIM, $P<0.001$, OH vs. WIN, $P=0.04$, KIM vs. WIN, $P=0.46$ ). Transcript levels of $P R-1$ were higher at 48 than at $24 \mathrm{~h}$ following the introduction of the caterpillars, but the extent of this increase was plant-population dependent.

\section{Discussion}

Both marker genes, $L O X$ and $P R$-1, were up-regulated in response to a single $P$. xylostella infestation in all three cabbage populations, whereas a single infestation by $B$. brassicae 


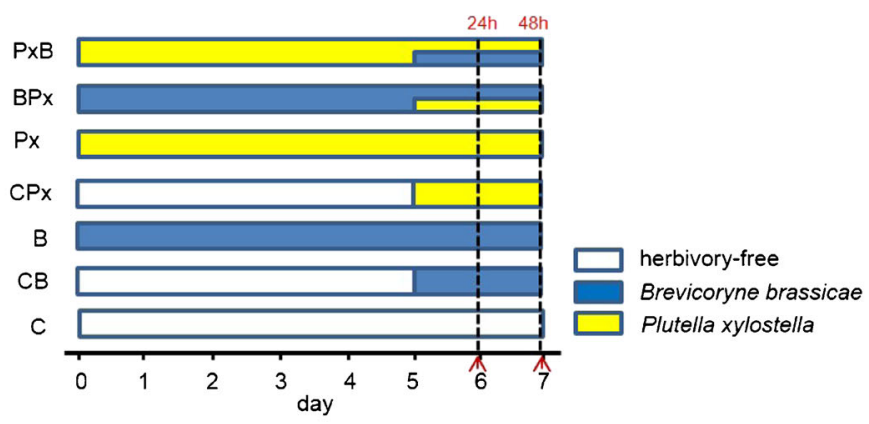

a

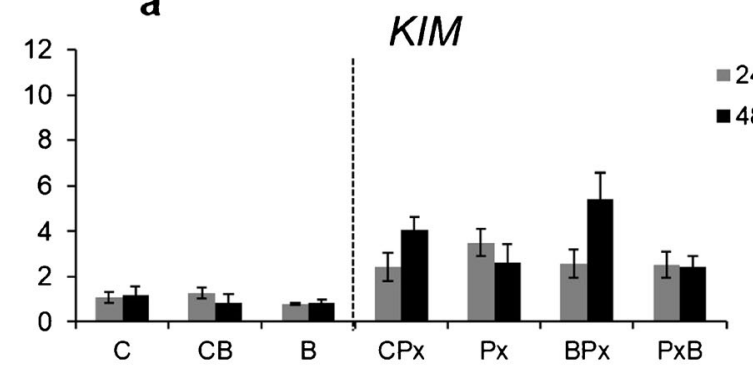

b

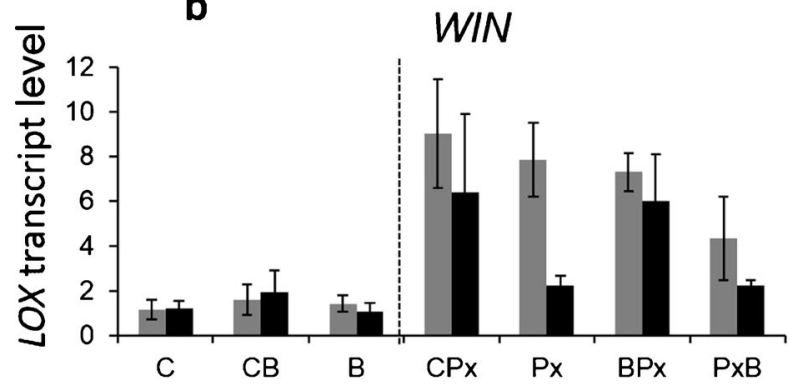

C

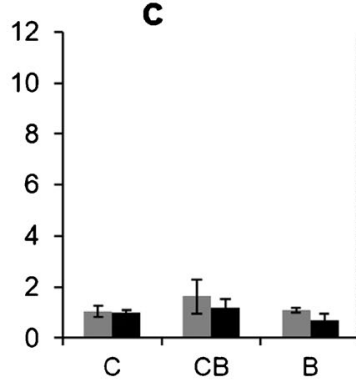

$\mathrm{OH}$
Fig. 2 Quantitative RT-PCR analysis of transcript levels of the jasmonic acid (JA)-responsive defense marker gene $L O X$ (panels a-c) and a salicylic acid (SA)-responsive defence marker gene $P R-1$ (panels d-f) in leaves of plants from three wild Brassica oleracea populations (KIM [a;d]; WIN [b;e]; OH [c;f]). Plants were infested with Plutella xylostella or Brevicoryne brassicae either at $\mathrm{d} 0(\mathrm{Px}$ and $\mathrm{B})$ or $\mathrm{d} 5$ (CPx and $\mathrm{CB})$, or they were dually infested with P. xylostella at $\mathrm{d} 0$ and with $B$. brassicae at $\mathrm{d} 5$ (PxB), or with $B$. brassicae at $\mathrm{d} 0$ and

aphids did not affect transcript levels of either of these two genes. In addition, dual infestation with aphids and P. xylostella caterpillars, simultaneously or separated in time (regardless of the order of infestation) had little or no effect on transcription levels of $L O X$ and $P R-1$ compared to the transcript levels in treatments with individual herbivores.
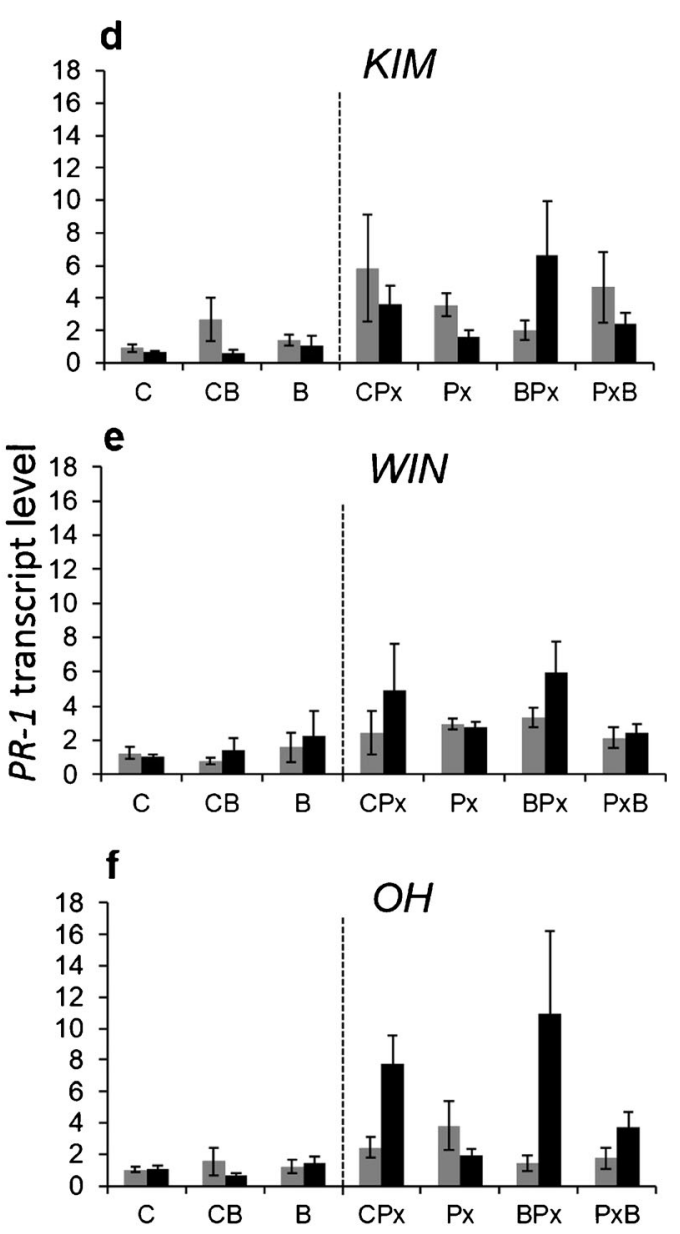

\section{Plant treatment}

with P. xylostella at d 5 (BPx). Gene expression was measured 24 and $48 \mathrm{~h}$ following treatment with the second herbivore. Gene transcript levels are shown as fold changes in mean relative expression compared to those in herbivore free control plants (C). Bars present means $\pm \operatorname{SE}(N=4)$. The temporal sequence of plant inoculation with different insect herbivore species is given in a schematic overview above the bar graphs. Sampling time points for gene transcript analysis are indicated by the red coloured arrows on the $\mathrm{X}$-axis

Caterpillar species differentially affected up-regulation of the two marker genes. As was found for P. xylostella, aphid presence did not interfere with transcription of $L O X$ and $P R-1$ in response to feeding by $P$. brassicae or $M$. brassicae caterpillars. The main effects were consistent across the three cabbage populations, although there were population-related 
Table 4 GLM analysis results of the main effects of plant population, herbivore treatment, time point and their interaction terms on the transcript level of lox and $p r-1$ in experiment $3^{a}$

\begin{tabular}{|c|c|c|c|c|c|}
\hline \multicolumn{6}{|c|}{ Experiment 3} \\
\hline Tested gene & Factor & N.d.f. & D.d.f & $F$ statistic & $P$ value \\
\hline \multirow[t]{15}{*}{$L O X$} & Plant population (1) & 2 & 108 & 37.69 & $<0.001$ \\
\hline & Caterpillar infestation (2) & 2 & 108 & 20.98 & $<0.001$ \\
\hline & B. brassicae infestation (3) & 1 & 108 & 2.82 & 0.096 \\
\hline & Time point (4) & 1 & 108 & 190.11 & $<0.001$ \\
\hline & Interaction $1 * 2$ & 4 & 108 & 2.17 & 0.077 \\
\hline & Interaction $1 * 3$ & 2 & 108 & 0.90 & 0.41 \\
\hline & Interaction $2 * 3$ & 2 & 108 & 2.50 & 0.087 \\
\hline & Interaction $1 * 4$ & 2 & 108 & 12.39 & $<0.001$ \\
\hline & Interaction $2 * 4$ & 2 & 108 & 0.81 & 0.45 \\
\hline & Interaction $3 * 4$ & 1 & 108 & 0.32 & 0.57 \\
\hline & Interaction $1 * 2 * 3$ & 4 & 108 & 1.66 & 0.16 \\
\hline & Interaction $1 * 2 * 4$ & 4 & 108 & 2.00 & 0.10 \\
\hline & Interaction $1 * 3 * 4$ & 2 & 108 & 1.47 & 0.23 \\
\hline & Interaction $2 * 3 * 4$ & 2 & 108 & 2.65 & 0.075 \\
\hline & Interaction $1 * 2 * 3 * 4$ & 4 & 108 & 1.25 & 0.30 \\
\hline \multirow[t]{16}{*}{$P R-1$} & Factor & N.d.f. & D.d.f & $F$ statistic & $P$ value \\
\hline & Plant population (1) & 2 & 108 & 6.83 & 0.002 \\
\hline & Caterpillar infestation (2) & 2 & 108 & 6.30 & 0.003 \\
\hline & B. brassicae infestation (3) & 1 & 108 & 0.07 & 0.799 \\
\hline & Time point (4) & 1 & 108 & 59.87 & $<0.001$ \\
\hline & Interaction $1 * 2$ & 4 & 108 & 2.43 & 0.052 \\
\hline & Interaction $1 * 3$ & 2 & 108 & 1.35 & 0.263 \\
\hline & Interaction $2 * 3$ & 2 & 108 & 1.78 & 0.174 \\
\hline & Interaction $1 * 4$ & 2 & 108 & 3.42 & 0.036 \\
\hline & Interaction $2 * 4$ & 2 & 108 & 0.05 & 0.948 \\
\hline & Interaction $3 * 4$ & 1 & 108 & 0.11 & 0.742 \\
\hline & Interaction $1 * 2 * 3$ & 4 & 108 & 1.40 & 0.238 \\
\hline & Interaction $1 * 2 * 4$ & 4 & 108 & 2.66 & 0.036 \\
\hline & Interaction $1 * 3 * 4$ & 2 & 108 & 1.14 & 0.324 \\
\hline & Interaction $2 * 3 * 4$ & 2 & 108 & 5.01 & 0.008 \\
\hline & Interaction $1 * 2 * 3 * 4$ & 4 & 108 & 0.10 & 0.983 \\
\hline
\end{tabular}

$P$-values in bold denote significant effects

${ }^{\mathrm{a}}$ In the statistical model, plant population had three levels (KIM, WIN, OH), treatment had seven levels (see Fig. 3) and time point had two levels (24 and 48 h)

differences in the temporal dynamics of $L O X$ and $P R-1$ transcription, in the response to the three caterpillar species, and also in the extent to which plants of the three populations up-regulated gene expression in response to the various herbivore treatments.

Based on negative SA-JA crosstalk, we hypothesized that aphid infestation would lead to higher transcript levels of SAresponsive genes and would suppress the transcription of JAresponsive genes in response to caterpillar attack. The temporal order of herbivore attack can further influence the timing and intensity of plant defense responses to aphid and caterpillar feeding and their interaction (Erb et al. 2011; Stam et al. 2014). In contrast to our hypothesis, the results of the present study show no effects of aphid infestation on the transcript levels of a JA- and a SA-responsive gene when plants were challenged by both $B$. brassicae and different caterpillar species, irrespective of the temporal sequence of aphid and caterpillar attack. The lack of interference with transcription of JA- or SAresponsive genes by aphid infestation on the $B$. oleracea plants may be attributed to: 1) a lack of effects of aphid infestation on SA production, as was also reported by Ali and Agrawal (2014) for Asclepias tuberosa. Low transcript levels of PR-1 in the present study may imply overall low activation of SA signalling in B. oleracea plants in response to aphid infestation. 2) Absence of negative crosstalk between SA and JA in B. oleracea. A review by Thaler et al. (2012) reported the absence of SA-JA antagonism in several plant species, e.g., Zea 

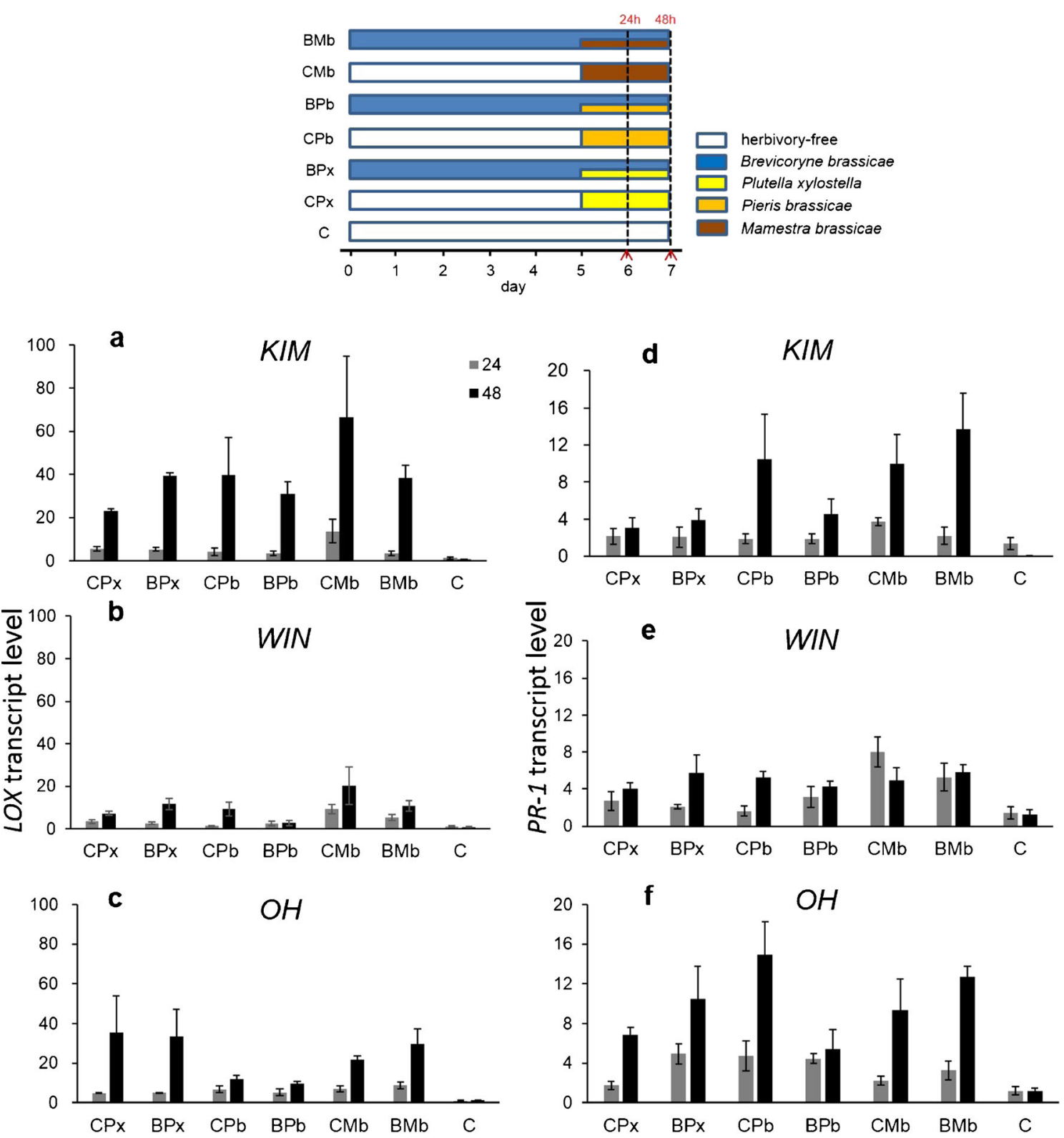

Plant treatment

Fig. 3 Quantitative RT-PCR analysis of transcript levels of the jasmonic acid (JA)-responsive defense marker gene $L O X$ (panels a-c) and a salicylic acid (SA)-responsive defense marker gene $P R-1$ (panels d-f) in leaves of wild Brassica oleracea populations (KIM [a;d]; WIN [b;e]; OH $[\mathbf{c} ; \mathbf{f}])$. Plants were infested with caterpillars of one of three lepidopteran species Plutella xylostella $(\mathrm{CPx})$, Pieris brassicae $(\mathrm{CPb})$, or Mamestra brassicae $(\mathrm{CMb})$ on $\mathrm{d} 5$, or they were dually infested with Brevicoryne brassicae at $\mathrm{d} 0$ and caterpillars on $\mathrm{d} 5(\mathrm{BPx}, \mathrm{BPb}$, and $\mathrm{BMb}$,

mays (Poaceae), Asclepias exaltata (Apocynaceae), and Picea abies (Pinaceae), suggesting that this phenomenon is not ubiquitous across taxa even when they are in the same family like A. thaliana and B. oleracea. 3) The temporal kinetics of JA- and SA-mediated defense induction and concomitant gene expression in wild cabbage may differ from those reported for the model plant $A$. thaliana. 4) In wild B. oleracea, genes other respectively). Gene expression was measured 24 and $48 \mathrm{~h}$ following treatment with the second herbivore. Gene transcript levels are shown as fold changes in mean relative expression compared to those in herbivore free control plants $(\mathrm{C})$. Bars present means $\pm \mathrm{SE}(N=4)$. The temporal sequence of plant inoculation with different insect herbivore species is given in a schematic overview above the bar graphs. Sampling time points for gene transcript analysis are indicated by the red colored arrows on the $\mathrm{X}$-axis

than $L O X$ and $P R-1$ are involved in JA-SA antagonism. Alternatively, the selected genes may not be involved in negative JA-SA cross talk in wild B. oleracea. 5) The duration of the time interval of aphid feeding ( 5 days) before the caterpillars were introduced onto the plants was not long enough to have a measurable effect on transcription levels of the genes examined. In some other systems, aphid feeding has been shown to take up 
to a week to elicit chemical defences (Appel et al. 2014; Mewis et al. 2005, 2006).

Aphid (B. brassicae) feeding alone had no effect on the transcript levels of either $P R-1$, a gene supposedly responsive to aphid feeding (De Vos et al. 2005) or LOX. This is consistent with data by Moran and Thompson (2001) who reported that $B$. brassicae did not induce responses associated with JAor SA-related metabolic processes in A. thaliana plants. Due to the stealthy feeding style of aphids and the minimal wounding they cause to plants, induction of SA in response to aphid herbivory occurs very locally, i.e., only at the site of aphid feeding, and, therefore, transcript levels of $P R-1$ may be low and difficult to detect (De Vos et al. 2005). Previous studies have reported that the saliva of aphids is rich in elicitors (Hogenhout and Bos 2011; Walling 2000). Both SA- and JA-responsive genes reacted to feeding by $B$. brassicae and M. persicae in Arabidopsis (Kusnierczyk et al. 2008, 2011; Moran and Thompson 2001). However, the aphid-induced responses of plants also can be aphid species-specific. For instance, $M$. persicae feeding induced SA-responsive genes in A. thaliana, whereas B. brassicae did not (Appel et al. 2014). Brevicoryne brassicae may have evolved to avoid inducing defensive responses in wild cabbage plants that are often attacked by this aphid in its natural habitat (Newton et al. 2009a), or it may manipulate the plant defense for its own benefit (Howe et al. 2007; Walling 2008). This also has been reported for a population of the herbivorous spider mite Tetranychus urticae that does not induce JA-regulated defenses in tomato that negatively affect spider mite performance (Kant et al. 2008).

Feeding by $P$. xylostella caterpillars significantly upregulated gene expression not only of $L O X$, but also of $P R-1$, irrespective of whether the caterpillars were feeding alone or together with aphids. Studies by Kroes et al. (2015) and Ehlting et al. (2008) showed similar results, confirming that $P$. xylostella induces the expression of both SA- and JA-responsive genes in Arabidopsis. Glucose oxidase, present in the saliva of Helicoverpa zea caterpillars, induces SA signalling, which leads to inhibition of JA signalling and eventually prevents the induction of nicotine in Nicotiana tabacum plants (Musser et al. 2002, 2005). In our study, not only infestation by $P$. xylostella, but also by two other lepidopteran species, $P$. brassicae and $M$. brassicae, consistently upregulated the expression of both $L O X$ and $P R-1$ genes on all three cabbage populations, regardless of the differences in dietary specialization and salivary elicitors (Felton 2008). In previous studies, it has been shown that both P. xylostella and P. brassicae, but not M. brassicae gained fitness benefits by feeding on wild and cultivated cabbage plants co-infested with $B$. brassicae aphids ( $\mathrm{Li}$ et al. 2014; Soler et al. 2012). However, as we did not record an effect of aphid infestation on the transcription of the JA-responsive gene $L O X$, it remains to be investigated whether the enhanced performance of P. xylostella and P. brassicae (Li et al. 2014; Soler et al. 2012) results from attenuation of JA-mediated defenses. Alternatively, negative interference between JA and SA may affect genes other than $L O X$ and $P R-1$ in wild B. oleracea.

The extent to which $L O X$ and $P R-1$ were up-regulated differed among plants infested by different species of caterpillars: infestation with $M$. brassicae up-regulated both genes more compared to infestation by $P$. brassicae or $P$. xylostella. Herbivores with a similar feeding mode tend to induce more similar transcriptome responses in A. thaliana plants than herbivores with a different feeding mode (Appel et al. 2014; Bidart-Bouzat and Kliebenstein 2011; Ehlting et al. 2008). However, for transcriptional responses induced by the chewing herbivores $P$. xylostella or $P$. rapae, only 32 to $40 \%$ of the genes were elicited commonly (Ehlting et al. 2008). Thus, induction of signal transduction components in plants may differ among herbivore species, even when the attacking herbivore species are from the same feeding guild (Bidart-Bouzat and Kliebenstein 2011; Diezel et al. 2009; Mewis et al. 2006). Although the chewing herbivores in this study are all members of the Lepidoptera, they differ in their feeding behavior. First and second instar P. xylostella larvae usually mine the leaf spongy mesophyll tissues, while later instars feed on the abaxial surface of leaves often leaving the upper epidermis intact (Sarfraz et al. 2005). Pieris brassicae larvae chew the leaf tissues gregariously, and initially cause a single damage site on the leaf. Mamestra brassicae larvae disperse immediately after egg hatching and then feed solitarily causing scattered sites of feeding damage on the leaves. It remains unknown to what extent the different feeding patterns of these caterpillars contribute to the differences in induced plant transcriptional responses.

At the plant population level, we found differences in the overall transcriptional responses of plants to the various treatments and also in the temporal dynamics of these responses. These population-related differences were not consistent, however, among the various experiments. This suggests that variation in conditions that could not be controlled, either related to the greenhouse environment or the plants themselves, may have resulted in population-specific variation in the response to the various treatments. These results reveal that the expression of genes involved in JA and SA defense signalling can be quite subtle and linking gene expression to responses occurring at a higher level of biological organization should be done with caution. Nevertheless, also at the population level, there is no evidence to support JA-SA antagonism based on transcript levels of the two marker genes.

The non-interactive effects of aphid and caterpillar infestation on the transcription levels of JA- and SA- responsive marker genes in the wild cabbage populations, regardless of the temporal sequence of both types of herbivory, implies that 
JA-SA antagonism may not occur ubiquitously in all plant taxa. In this study, we examined only two genes that are considered representative for the two signalling pathways. Future studies should aim to investigate genes with different functions, and genes that are transcribed along the sequence of molecular events that are activated in response to herbivory. The interaction between the JA and SA signalling pathways is likely to be far more complex involving various genes of which some interact antagonistically and others do not.

Acknowledgments We thank Patrick Verbaarschot for instructions for qRT-PCR analysis; Enric Frago for discussion of the data; Léon Westerd, André Gidding, and Joop Woelke for rearing the insects; Unifarm staff for assistance in the greenhouse. This study was funded by a Top GO grant (No.840.10.010) from the Netherlands Organization for Scientific Research (NWO) to MD.

Open Access This article is distributed under the terms of the Creative Commons Attribution 4.0 International License (http:// creativecommons.org/licenses/by/4.0/), which permits unrestricted use, distribution, and reproduction in any medium, provided you give appropriate credit to the original author(s) and the source, provide a link to the Creative Commons license, and indicate if changes were made.

\section{References}

Agrawal AA (1999) Induced plant defense: Evolution of induction and adaptive phenotypic plasticity. In: Agrawal, AA, Tuzun, S, Bent, E (eds) Inducible plant defenses against pathogens and herbivores: Biochemistry, ecology, and agriculture American Phytopathological Society Press, St Paul, MN, pp 251-268

Ali JG, Agrawal AA (2014) Asymmetry of plant-mediated interactions between specialist aphids and caterpillars on two milkweeds. Funct Ecol 28:1404-1412

Appel HM et al. (2014) Transcriptional responses of Arabidopsis thaliana to chewing and sucking insect herbivores. Front Plant Sci 5:1-20

Bell E, Creelman RA, Mullet JE (1995) A chloroplast lipoxygenase is required for wound-induced jasmonic acid accumulation in Arabidopsis. Proc Natl Acad Sci U S A 92:8675-8679

Bidart-Bouzat MG, Kliebenstein D (2011) An ecological genomic approach challenging the paradigm of differential plant responses to specialist versus generalist insect herbivores. Oecologia 167:677-689

De Vos M et al. (2005) Signal signature and transcriptome changes of Arabidopsis during pathogen and insect attack. Mol Plant Microbe Int 18:923-937

Dicke M, Baldwin IT (2010) The evolutionary context for herbivoreinduced plant volatiles: beyond the "cry for help. Trends Plant Sci $15: 167-175$

Diezel C, von Dahl CC, Gaquerel E, Baldwin IT (2009) Different lepidopteran elicitors account for cross-talk in herbivory-induced phytohormone signaling. Plant Physiol 150:1576-1586

Ehlting J, Chowrira SG, Mattheus N, Aeschliman DS, Arimura G, Bohlmann J (2008) Comparative transcriptome analysis of Arabidopsis thaliana infested by diamond back moth (Plutella xylostella) larvae reveals signatures of stress response, secondary metabolism, and signalling. BMC Genomics 9:154.

Erb M, Robert CAM, Hibbard BE, Turlings TCJ (2011) Sequence of arrival determines plant-mediated interactions between herbivores. J Ecol 99:7-15
Erb M, Meldau S, Howe GA (2012) Role of phytohormones in insectspecific plant reactions. Trends Plant Sci 17:250-259

Felton, GW (2008) Caterpillar secretions and induced plant responses. Springer, Hohenheim, Germany

Gols R, Wagenaar R, Bukovinszky T, van Dam NM, Dicke M, Bullock JM, Harvey JA (2008) Genetic variation in defense chemistry in wild cabbages affects herbivores and their endoparasitoids. Ecology 89:1616-1626

Harvey JA, Witjes LMA, Benkirane M, Duyts H, Wagenaar R (2007) Nutritional suitability and ecological relevance of Arabidopsis thaliana and Brassica oleracea as foodplants for the cabbage butterfly, Pieris rapae. Plant Ecol 189:117-126

Harvey JA, van Dam NM, Raaijmakers CE, Bullock JM, Gols R (2011) Tri-trophic effects of inter- and intra-population variation in defence chemistry of wild cabbage (Brassica oleracea. Oecologia 166:421431

Hogenhout SA, Bos JI (2011) Effector proteins that modulate plant-insect interactions. Curr Opin Plant Biol 14:422-428

Howe GA, Jander G (2008) Plant immunity to insect herbivores. Annu Rev Plant Biol 59:41-66

Howe GA, Kim JH, Jander G (2007) Biochemistry and molecular biology of Arabidopsis-Aphid interactions. BioEssays 29:871-883

Jirage D, Zhou N, Cooper B, Clarke JD, Dong XN, Glazebrook J (2001) Constitutive salicylic acid-dependent signaling in cpr1 and cpr6 mutants requires PAD4. Plant J 26:395-407

Kant MR, Sabelis MW, Haring MA, Schuurink RC (2008) Intraspecific variation in a generalist herbivore accounts for differential induction and impact of host plant defences. Proc R Soc B 275:443-452

Karban R, Baldwin I (1997) Induced responses to herbivory University of Chicago Press. Chicago, Illinois, USA

Kessler A, Baldwin IT (2002) Plant responses to insect herbivory: the emerging molecular analysis. Annu Rev Plant Biol 53:299-328

Kliebenstein DJ, Kroymann J, Brown P, Figuth A, Pedersen D, Gershenzon J, Mitchell-Olds T (2001) Genetic control of natural variation in Arabidopsis glucosinolate accumulation. Plant Physiol 126:811-825

Koornneef A, Pieterse CMJ (2008) Cross talk in defense signaling. Plant Physiol 146:839-844

Kroes A, van Loon JJ, Dicke M (2015) Density-dependent interference of aphids with caterpillar-induced defenses in Arabidopsis: involvement of phytohormones and transcription factors. Plant Cell Physiol 56:98-106

Kusnierczyk A, Winge P, Jorstad TS, Troczynska J, Rossiter JT, Bones AM (2008) Towards global understanding of plant defence against aphids-timing and dynamics of early Arabidopsis defence responses to cabbage aphid (Brevicoryne brassicae) attack. Plant Cell Environ 31:1097-1115

Kusnierczyk A, Tran DHT, Winge P, Jorstad TS, Reese JC, Troczynska J, Bones AM (2011) Testing the importance of jasmonate signalling in induction of plant defences upon cabbage aphid (Brevicoryne brassicae) attack. BMC Genomics 12:423.

Li Y, Dicke M, Harvey J, Gols R (2014) Intra-specific variation in wild Brassica oleracea for aphid-induced plant responses and consequences for caterpillar-parasitoid interactions. Oecologia 174:853-862

Livak KJ, Schmittgen TD (2001) Analysis of relative gene expression data using real-time quantitative PCR and the $2-\Delta \Delta \mathrm{CT}$ method. Methods 25:402-408

Mewis I, Appel HM, Hom A, Raina R, Schultz JC (2005) Major signaling pathways modulate Arabidopsis glucosinolate accumulation and response to both phloem-feeding and chewing insects. Plant Physiol 138:1149-1162

Mewis I, Tokuhisa JG, Schultz JC, Appel HM, Ulrichs C, Gershenzon J (2006) Gene expression and glucosinolate accumulation in Arabidopsis thaliana in response to generalist and specialist 
herbivores of different feeding guilds and the role of defense signaling pathways. Phytochemistry 67:2450-2462

Moran PJ, Thompson GA (2001) Molecular responses to aphid feeding in Arabidopsis in relation to plant defense pathways. Plant Physiol 125:1074-1085

Mouttet R, Kaplan I, Bearez P, Amiens-Desneux E, Desneux N (2013) Spatiotemporal patterns of induced resistance and susceptibility linking diverse plant parasites. Oecologia 173:1379-1386

Musser RO, Hum-Musser SM, Eichenseer H, Peiffer M, Ervin G, Murphy JB, Felton GW (2002) Herbivory: Caterpillar saliva beats plant defences. Nature 416:599-600

Musser RO, Cipollini DF, Hum-Musser SM, Williams SA, Brown JK, Felton GW (2005) Evidence that the caterpillar salivary enzyme glucose oxidase provides herbivore offense in Solanaceous plants. Arch Insect Biochem Physiol 58:128-137

Newton EL, Bullock JM, Hodgson D (2009a) Bottom-up effects of glucosinolate variation on aphid colony dynamics in wild cabbage populations. Ecol Entomol 34:614-623

Newton EL, Bullock JM, Hodgson DJ (2009b) Glucosinolate polymorphism in wild cabbage (Brassica oleracea) influences the structure of herbivore communities. Oecologia 160:63-76

Pieterse CMJ, Dicke M (2007) Plant interactions with microbes and insects: from molecular mechanisms to ecology. Trends Plant Sci 12:564-569

Pieterse CM, Leon-Reyes A, Van der Ent S, Van Wees SC (2009) Networking by small-molecule hormones in plant immunity. Nat Chem Biol 5:308-316

Pieterse, CMJ, Van der Does, D, Zamioudis, C, Leon-Reyes, A, Van Wees, SCM (2012) Hormonal modulation of plant immunity. Annu Rev Cell Dev Biol 28:28.21-28.33

Poelman EH, Zheng SJ, Zhang Z, Heemskerk NM, Cortesero AM, Dicke M (2011) Parasitoid-specific induction of plant responses to parasitized herbivores affects colonization by subsequent herbivores. Proc Natl Acad Sci U S A 108:19647-19652

Rodriguez-Saona CR, Musser RO, Vogel H, Hum-Musser SM, Thaler JS (2010) Molecular, biochemical, and organismal analyses of tomato plants simultaneously attacked by herbivores from two feeding guilds. J Chem Ecol 36:1043-1057

Sarfraz M, Keddie AB, Dosdall LM (2005) Biological control of the diamondback moth, Plutella xylostella: A review. Biocontrol Sci Techn 15:763-789

Schmidt DD, Voelckel C, Hartl M, Schmidt S, Baldwin IT (2005) Specificity in ecological interactions. Attack from the same lepidopteran herbivore results in species-specific transcriptional responses in two solanaceous host plants. Plant Physiol 138:1763-1773
Schoonhoven, LM, van Loon, J, Dicke, M (2005) Insect-plant biology. 2nd edn. Oxford University Press, Oxford

Soler R, Badenes-Perez FR, Broekgaarden C, Zheng SJ, David A, Boland W, Dicke M (2012) Plant-mediated facilitation between a leaffeeding and a phloem-feeding insect in a brassicaceous plant: from insect performance to gene transcription. Funct Ecol 26:156-166

Stam JM, Kroes A, Li Y, Gols R, van Loon JJA, Poelman EH, Dicke M (2014) Plant interactions with multiple insect herbivores: from community to genes. Annu Rev Plant Biol 65:689-713

Thaler JS, Humphrey PT, Whiteman NK (2012) Evolution of jasmonate and salicylate signal crosstalk. Trends Plant Sci 17:260-270

Traw M, Kim J, Enright S, Cipollini D, Bergelson J (2003) Negative cross-talk between salicylate-and jasmonate-mediated pathways in the Wassilewskija ecotype of Arabidopsis thaliana. Mol Ecol 12: $1125-1135$

Voelckel C, Baldwin IT (2004) Herbivore-induced plant vaccination. Part II. Array-studies reveal the transience of herbivore-specific transcriptional imprints and a distinct imprint from stress combinations. Plant J 38:650-663

Walling LL (2000) The myriad plant responses to herbivores. J Plant Growth Regul 19:195-216

Walling LL (2008) Avoiding effective defenses: strategies employed by phloem-feeding insects. Plant Physiol 146:859-866

Wu J, Baldwin IT (2009) Herbivory-induced signalling in plants: perception and action. Plant Cell Environ 32:1161-1174

Wu J, Baldwin IT (2010) New insights into plant responses to the attack from insect herbivores. Annu Rev Genet 44:1-24

Wu J, Hettenhausen C, Schuman MC, Baldwin IT (2008) A comparison of two Nicotiana attenuata accessions reveals large differences in signaling induced by oral secretions of the specialist herbivore Manduca sexta. Plant Physiol 146:927-939

Zhang PJ, Zheng SJ, van Loon JJ, Boland W, David A, Mumm R, Dicke M (2009) Whiteflies interfere with indirect plant defense against spider mites in lima bean. Proc Natl Acad Sci U S A 106:2120221207

Zheng SJ, van Dijk JP, Bruinsma M, Dicke M (2007) Sensitivity and speed of induced defense of cabbage (Brassica oleracea L.): Dynamics of BoLOX expression patterns during insect and pathogen attack. Mol Plant Microbe Int 20:1332-1345

Zhu F, Broekgaarden C, Weldegergis BT, Harvey JA, Vosman B, Dicke M, Poelman EH (2015) Parasitism overrides herbivore identity allowing hyperparasitoids to locate their parasitoid host using herbivore-induced plant volatiles. Mol Ecol 24:2886-2899 